\title{
Intervention measures applied to control brucellosis in Libya: The needs for effective control programs
}

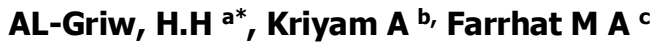 \\ a Department of Microbiology and Parasitology, Faculty of Veterinary Medicine, Tripoli University, Tripoli, Libya \\ b,c Department of Microbiology, National Centre of Animal Health, Tripoli, Libya \\ *Corresponding author: Huda Hassan Al-Griw (huda_algriw@hotmail.com)
}

How to cite this article: AL-Griw,H.H. et al. Intervention measures applied to control brucellosis in Libya: The needs for effective control programs. Veterinary Medicine and Public Health Journal 1(3); 2020:75-80.

DOI: https://doi.org/10.31559/vmph2020.1.3.1

Received Date: 23/4/2020

Accepted Date: 15/6/2020

\begin{abstract}
Efforts to control brucellosis in Libya have been employed for a long time over the last century. Although the international organisations such as FAO, OIE and WHO have offered vital help and cooperation, the data documented has rarely been addressed and utilised as a guidance for further control and eradication strategies. We aimed to retrospectively study and analyse the data available at the National Centre of Animal Health (NCAH) to identify the gaps and the shortcomings in the employed control programs and eradication systems and stimulate discussion on future strategies. Row data was obtained from the records of surveillance systems and serological results conducted at the NCAH. The data was analysed and tabulated using Microsoft Excel sheets. Whenever the information was missing, or incomplete, online database searches fulfilled the gaps. The data revealed that the disease continued to be endemic in the country with relatively higher rate of infection in small ruminants than in cattle and camels. Despite the efforts being in place to control brucellosis in the country, it seems that the intervention programs applied to control livestock brucellosis although it maintained low rate of infection were not effective to eradicate the disease completely.
\end{abstract}

Keywords: brucellosis; Libya; control programs.

\section{Introduction}

Brucellosis has been recognized during the last century as a serious zoonotic disease in most countries of the near east region causing massive economic loss. Due to intensive importation of the livestock for breeding purposes, the incidence of animal and human brucellosis faced sharp increase in many of these countries. The strategy of control and prevention of transmission of brucellosis depends on the extent and the epidemiology of the disease in the target area, though non-specific measures could be implemented due to the ability of the causative organism to persist for a long time. Some countries succeeded in efforts to eradicate the disease through several measures, starting with the prevention of the disease transmission through heat killing of the organism from milk and milk's products, utilising proper diagnostic techniques that are capable to distinguish among infected animals and control of animal herds through vaccination and calling of infected animals (Moreno, 2014). Humans are not the primary host for brucellosis and no vaccine is available to control the disease. Although combined antibiotic treatment of human brucellosis is available, recurrence of the infection is always suspected due to the persistent nature of the Brucella organism in the lymph nodes (Godfroid et al., 2005). Therefore, prevention of human brucellosis can only be achieved by the control of the disease in livestock animals (Pérez-Sancho et al., 2015).

One successful control strategy in small ruminants is the use of $\operatorname{Rev} 1$ vaccine. This would reduce the level of infection to a reasonable level, allows the use of testing and slaughtering program in combination with vaccination and implementation of extensive biosecurity measures. These include surveillance programmes and sustained elimination of the infected animals and the source of infection, 
through the test-and-slaughter policies and control of animal's movements until complete eradication of the disease is achieved (FAO/WHO/OIE, 1995, Olsen and Stoffregen, 2005, Blasco, 2010). However, the use of Rev I vaccine is hampered with the risk of vaccinal abortion and persistence of serological reactors which interfere with the forthcoming surveillance programs (Mustafa and Abusowa, 1993). In addition to the hazard of human infection particularly those whom in contact with animals such as veterinarians and field workers (Ullah et al., 2014, Wernery, 2014). Although vaccination and culling of infected animals have been successfully used to eradicate brucellosis in the USA, this strategy is difficult to be implied in some countries that are unable to offer adequate economic compensation of the culled livestock or in absence of public health awareness with the importance of removing the infected animals (Yang et al., 2013).

Brucellosis in Libya is an endemic disease in man and among livestock animals mostly in small ruminants (Al-Griw et al., 2017). Brucella melitensis biovar 1 and 2 has been reported as the main etiological agent of the disease in the country (Refai, 2002). Libya in collaboration with international organisation such as FAO, OIE and WHO have long term efforts to control the disease in the country. Their aim was to improve the livestock productivity and enhance management of veterinary service and control of transboundary animal diseases including animal brucellosis, (FAO, 2011, OIE, 2002). In this setting, we present an appraisal of the main efforts that have been employed to control and eradicate brucellosis in the country over more than 30 years past. The objective is to identify the gaps and the shortcomings in the employed control and eradication systems and stimulate discussion on future strategies.

\section{Methods}

This is a retrospective study aimed to point out the activities and the strategies applied to control brucellosis in Libya from the 1980s up to 2010 just before the revolution in Libya when all the official systems collapsed. The accumulated epidemiological row data was obtained from the records of surveillance systems and serological results conducted at the National Centre of Animal Health (NCAH, Tripoli branch), were analysed and tabulated using Microsoft Excel sheets. Whenever the information was missing or incomplete, internet searches of the published data was accomplished. The prevalence of brucellosis in the studied areas were calculated as the number of positive cases divided by the number of tested animals.

\section{Results and Discussion}

\section{Intervention programs applied to combat small ruminant's brucellosis}

Since 1953, Libya has joined the FAO and has been benefiting from its technical assistance, through various activities and several national projects (e. g.
"Assistance to the Secretariat of Agriculture \& Animal Wealth", "Training in Veterinary Service - Phase II)" and "Support of Veterinary Services Phase III and IV"). The last was established as UTFN/LIB/025 with a budget of 5,160,825 US\$ in 1986 among 6 UTF projects (FAO, 2011).

Among the activities of the FAO UTFN/LIB/025 projects, Chinese Brucella suis S2 vaccine was produced in 1983. This vaccine was then administrated as a field trial in the form of drench to 446 ewes, 20 adult goats and 51 lambs. Ninety-two percent (92\%) of vaccinated animals became serologically positive in 4 weeks and the serological after-effects were persisted up to a one-year post vaccination. No single case of abortion was noted throughout the lamping season in all vaccinated animals. The vaccine strain was not transmitted to the non-vaccinated control animals as indicated with negative serological tests during the experiment. Randomly selected 27 weeks vaccinated and control animals were injected intraocularly with 5 X $10^{6} \mathrm{CFU}$ of highly virulent locally isolated $B$. melitensis biovar 2 , followed by administration of an equal dose of $B$. melitensis biovar 1 in 10 days' gap. A protection rate of $71 \%$ in goats was obtained and the abortion rate reduced to $44 \%$ Vs $100 \%$. The trial concluded that the vaccine is safe, easy to apply and would be of value as an emergency control of the disease in infected flock (Mustafa and Abusowa, 1993).

Following successful production of the local Chinese Brucella suis S2 vaccine, a trial study was conducted between March and July 1989 in small groups of sheep and goats to study the usefulness of using this vaccine locally. A mass vaccination campaign was established in the western region in the country. Random selection of small ruminants (one in 10 animals) were tested to determine the prevalence of the disease in the region (Table 1). The campaign comprised vaccination of 213933 animals from 932 herds distributed in three main regions, Nalut, Kabaw and Zwara regions. The method of vaccination and dose used was in accordance with the procedure of Mustafa and Abusowa field trial (Mustafa and Abusowa, 1993). The recorded data showed that the number of vaccinated sheep was higher than the goats throughout the three regions (135501 to 78432 respectively). This may attribute to the desire of most people breeding sheep more than goats, preferring to eat sheep meat and limiting the eating of goat meat to the spring season while utilizing goat milk to produce Ghee.

Table (1): Vaccination Campaign of Sheep and Goats in some Western Regions Between March and July 1989

\begin{tabular}{|l|r|r|r|r|}
\hline Region & Number of herds & $\begin{array}{c}\text { Number of } \\
\text { vaccinated } \\
\text { sheep }\end{array}$ & $\begin{array}{c}\text { Number of } \\
\text { vaccinated } \\
\text { goats }\end{array}$ & Total \\
\hline Nalut & 246 & 56564 & 26964 & $\mathbf{8 3 5 2 8}$ \\
\hline Kabaw & 315 & 54175 & 34323 & $\mathbf{8 8 4 9 8}$ \\
\hline Zwara & 371 & 23660 & 10707 & $\mathbf{3 4 3 6 7}$ \\
\hline Total & $\mathbf{9 3 2}$ & $\mathbf{1 3 5 5 0 1}$ & $\mathbf{7 8 4 3 2}$ & $\mathbf{2 1 3 9 3 3}$ \\
\hline
\end{tabular}


Unfortunately, no available data traced back the duration of serological after-effects and the effectiveness of this program on reduction of the rate of infection. Vaccination alone does not complete the eradication of brucellosis. It is only after a long period of mass vaccination (5-10 years) that the number of cases of brucellosis would be reduced by at least $80 \%$. Thereafter, it would be possible to use the testslaughter program and vaccination of young animals to eventually achieve the eradication of the disease (FAO/WHO/OIE, 1995, Blasco, 2010). The poor delivery and the failure to continue these programs although the efforts applied may attribute to the lack of planning, statistics, policy design, implementation and monitoring programmes. The Ministry of Agriculture has suffered institutional instability and frequent changes in managements. The efforts to improve project operation were hampered by the lack of funds and the project was eventually terminated. It was only in 2006 when the Ministry of Agriculture, Animal and Marine Wealth was reestablished following nearly 16 years of disaggregation of authority within the sector (FAO, 2011).

In 2007, the rate of screening tests for Brucella in small ruminants in Libya was raised following an authorisation of cash compensation for culled animals by the government. Data documented from a surveillance program in Sirt region showed that, the proportion of positive cases identified for brucellosis in sheep was $8.3 \%$ (206 positive cases out of 2483 animal tested) whereas a percentage of $7.4 \%$ (214 positive cases out of 2876 animal tested) was recorded in goats. However, the program faced difficulties because the owners did not accept the amount of compensation that was 69 Libyan Dinar (L.D) per goat and 100 L.D per sheep and refused to cull the positive cases of their animals.

In 2008-2009, 1425 and 2347 blood samples from sheep and goats, respectively were randomly collected from different localities in Libya as a part of a surveillance program conducted to combat livestock brucellosis in the country. A prevalence rate of $8.3 \%$ in sheep and $14.8 \%$ in goats were documented. The rate of infection in sheep matched the rate obtained in 2007. However, it seems that the program gained from removing the positive cases through the test and slaughter system and the rate of infection was reduced in goats to $2.0 \%$ when 1003 randomly re-collected blood samples from the same region at the end of 2009 were tested.

In 2010, a research study to investigate the seroprevelence of Brucella in small ruminant in the three different regions in the country was conducted as part of a research project funded by Libyan Agriculture Research Centre through the cooperation project with the international centre for Agriculture Research in Dry Areas (ICARDA). The project aimed to screen for 4 diseases, blue tongue, toxoplasmosis, chlamydiosis and brucellosis. Collectively, 1487, 360 and 383 blood samples (overall 2230 samples) were collected from western, middle and south regions, respectively. A total of 1787 sheep and goats' samples from the three regions were screened for brucellosis. The results showed that a seropositive prevalence rates of $4 \%$ was reported in the western region while no cases were detected in the two other regions (unpublished NCAH data).

\section{Intervention programs applied to combat bovine brucellosis}

The control programmes of bovine brucellosis were introduced in Libya in 1988 among the veterinary public health activities (VPH) defined and founded by WHO (The World Health Organisation) in the countries of the Eastern Mediterranean region as well as several North African countries. Serological tests revealed infection of about $1 \%$. Control measures included test-and-slaughter of positive reactors with compensation funds for owners. However, no vaccinations were carried out as protection from further infection (Polydorou, 1992).

Between 1997 and 2009, a National Bovine Brucellosis Eradication Programme was conducted in the whole country to prevent the transmission of the disease to humans. The programme involved testing and slaughtering the positive reactors and immediate compensation of the farmers, in addition to following up the positive herd at 21 days, 3 months and 6 months before the farm is considered brucellosis free. The results were encouraging; the prevalence rate was $0.1 \%$ (215 positive cases out of 166388 animals tested) by the end of 1999 (FAO, 1999). The programme continued a couple of years later and then ceased. The reason for termination of this programme was not clear but again the institutional instability and frequent changes in managements, lack and corruption of the compensation funds for owners, may play important roles for such failure. Figure 1 presents the sero-surveillance results conducted by the NCAH between 1997 and 2001 in most bovine breading farms distributed throughout the country.

In the following years (i. e. between 2002 and 2009 ), the number of animals tested was notably reduced that result in fluctuation in the proportion of seropositive animals (Table 2). In fact, the number of animals tested were not enough to drown a conclusion about the extent of infection in the years of estimation. Exact estimation of the animals to be tested for an effective intervention control program are required (Hegazy et al., 2009, Naletoski et al., 2010). In the available data, there was inconsistency between the number of expected animals to be tested and the number of sampled animals. The discrepancy of the rate of infection raises an important question 
whether an official control programme was in charge to supervise the veterinary practise at that time.

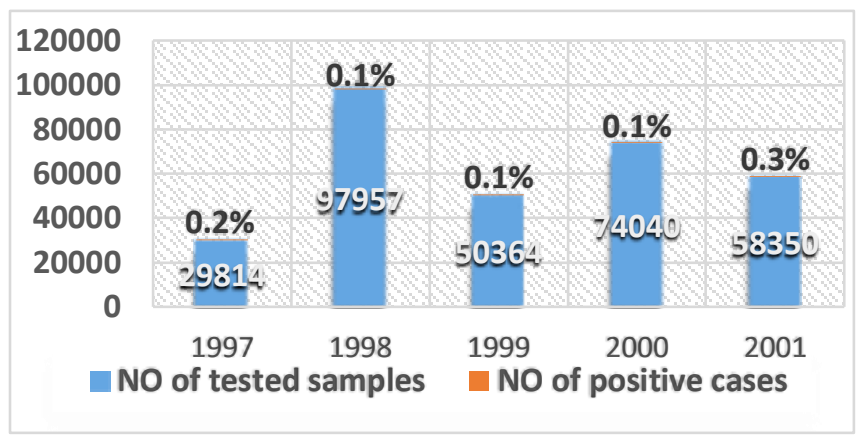

Figure (1): Prevalence of bovine brucellosis between 1997 and 2001

Table (2): The rate of brucellosis in cattle between 2002 and 2009

\begin{tabular}{|c|c|c|c|}
\hline Year & $\begin{array}{c}\text { Tested } \\
\text { samples }\end{array}$ & $\begin{array}{c}\text { Sero-positive } \\
\text { cases }\end{array}$ & $\begin{array}{c}\text { Proportion of } \\
\text { positive cases }\end{array}$ \\
\hline 2002 & 3475 & 3 & $0.1 \%$ \\
\hline 2003 & 3230 & 1 & $0.0 \%$ \\
\hline 2004 & 658 & 2 & $0.3 \%$ \\
\hline 2005 & 1292 & 5 & $0.4 \%$ \\
\hline 2006 & 37 & 1 & $2.7 \%$ \\
\hline 2007 & 353 & 3 & $0.8 \%$ \\
\hline 2008 & 929 & 0 & $0.0 \%$ \\
\hline 2009 & 1295 & 2 & $0.2 \%$ \\
\hline
\end{tabular}

\section{Intervention programs applied to combat camels' brucellosis}

Camel brucellosis pose serious hazard to public health, particularly in countries with extensive camels husbandry (Wernery, 2014). Human infection due to camel brucellosis are mainly occupationally acquired (Gwida et al., 2012). Human infection is also known to occur due to consumption of unpasteurised camel milk on the believes that camel milk has a curative effect on digestive system. B. melitensis biovar 1 has been isolated from camel milk in Libya (Gameel et al., 1993). Although, camels are not primary hosts for brucellosis, cross transmission frequently occurs when camels are raised in close contact with small ruminants and cattle (Wernery, 2014, Gwida et al., 2012). Therefore, the extant of the prevalence rate for camels brucellosis depends on the control of the primary hosts livestock particularly that infected camels in most cases are not culled (Wernery, 2014). Most camels in Libya are imported from Sudan and United Arab Emirates which are known to be endemic regions for brucellosis (Gwida et al., 2011). Therefore, control of cross border importation and movement of the camels into the country are necessary to reduce the incidence of the disease. Camel brucellosis was reported in Libya since 1990 (Azwai et al., 2001, Ben Faraj, 1990, ElBoshy et al., 2009, Gameel et al., 1993, Hosni and Aboudaya, 1992). However, the only active surveillance programs commenced to combat camel brucellosis involving the whole country was preformed between 2002 and 2007 (Table 3). The commonly used serological testes to detect camel brucellosis was Rose bangle test, serum agglutination test and complement fixation tests. The highest prevalence rate was in 2003 at 1\% (481 positive cases out of 46597 animals tested). While, the lowest percentage was recorded in 2006 with seropositive rate of $0.2 \%$ ( 7 positive cases out of 2890 animal tested). The study however was of limited value because the information whether the animals were local or imported, which of control program was implemented (e.g. test and slighter) was not well documented.

Table (3): Distribution of percentage of brucellosis in Camels cases according to the year of survey

\begin{tabular}{|l|c|c|c|}
\hline Year & $\begin{array}{l}\text { Number of } \\
\text { tested samples }\end{array}$ & $\begin{array}{l}\text { Number of } \\
\text { positive } \\
\text { cases }\end{array}$ & $\begin{array}{l}\text { Proportion of } \\
\text { positive cases }\end{array}$ \\
\hline 2002 & 60645 & 313 & $0.5 \%$ \\
\hline 2003 & 46597 & 481 & $1.0 \%$ \\
\hline 2004 & 3163 & 27 & $0.9 \%$ \\
\hline 2005 & 1584 & 6 & $0.4 \%$ \\
\hline 2006 & 2890 & 7 & $0.2 \%$ \\
\hline 2007 & 2019 & 11 & $0.5 \%$ \\
\hline 2008 & 2860 & 10 & $0.3 \%$ \\
\hline 2009 & 2590 & 21 & $0.8 \%$ \\
\hline
\end{tabular}

\section{Human brucellosis}

Despite, the establishment of the Zoonosis Control Centre since 1988-1989, which dealt with the most important zoonotic disease in Libya, the National Centre of Animal Health ( $\mathrm{NCAH}$ ) was recognised as a reference laboratory for human brucellosis. An analysis of serological results of samples that was documented in NCAH between 1983 until 2008 disclosed an overall percentage of human brucellosis of $50 \%$ (1719 positive cases out of 3423 suspected cases). These samples were taken from the suspected infected cases presented in the Zoonosis Control Centre in Alzawiya Street hospital from different municipalities in the western region of Libya and sent to the NCAH to perform the suitable serological tests. This includes Rose Bangle test (RBT), serum agglutination test (SAT) and enzyme linked sorbent immuno assay ELSIA. (Al Toumei, 2012). The results of this analysis revealed that the trends of seropositive proportion of human fluctuating brucellosis appeared to be in general on decline (Figure 2). The annually recorded data revealed a relatively higher infection rate between 1983 and 1988 followed by a decrease in the rate of infection in the following years. The lowest rate of infection was recorded in 1997, the year when the National Bovine Brucellosis Eradication Programme was started. The gradual reduction of the annually reported human cases of brucellosis may reflect the level of awareness of the disease in parallel with the control programmes campaign for combat brucellosis in livestock. Various variables were studied to determine the risk factor in association with the disease occurrence. Analysis of the data obtained revealed that the rate of infection in males was $60.7 \%$ 
but there was no significant statistical difference between both sexes. The analysis of the results also revealed that the rate of infection was higher in the middle age groups (mean $=32.5$ years). Although the disease may occur in all seasons, the infection rates were mostly in the spring season and early summer. This may have a strong connection with the lamping season particularly in small ruminants where livestock keepers and field workers (occupational exposure) assess in parturition and would be in close contact with the infected animals. The high percentage of infection in this period may have been also related to the consumption of unpasteurized cheese or milk, as a large amount of the Brucella organisms are shed from infected lactating animals in their milk and vaginal excretion following parturition or abortion and within aborted fetus (Ebrahimi et al., 2014, Zhang et al., 2014).

\section{Figure (2): Trends of human brucellosis in western region of Libya between 1983 and 2008 Adapted from (Al Toumei, 2012)}

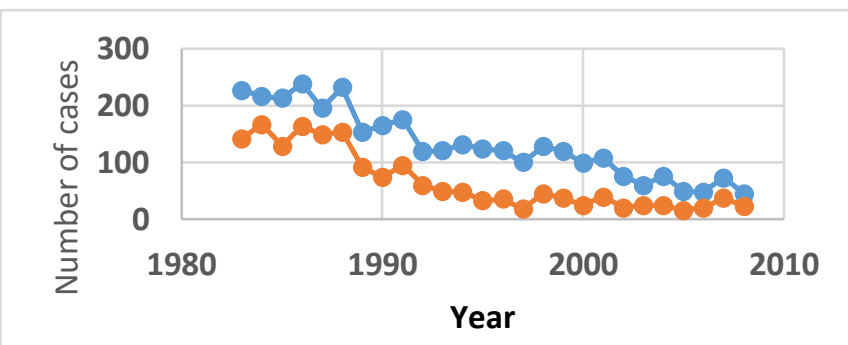

- No of suspected cases - No of positive cases

\section{Conclusion}

Despite the efforts being in place to control brucellosis in Libya, the disease continued to be endemic in the country with relatively higher rates of infection in small ruminants than in cattle and camels. It seems that the intervention programs applied to control livestock brucellosis in Libya although it maintained a low rate of infection, were not effective to eradicate the disease completely. There are many points drown from this study that need to be taken into consideration in any further intervention programs in the country.

1. The lack of current detailed epidemiological studies particularly in small ruminants strongly suggests the needs to re-assess the prevalence of the disease in the whole country. This would help the policy makers look for alternative strategies.

2. An important key role for successful surveillance programs is looking for proper epidemiologists who set the study designs and the standardised methods to estimate the seroprevelence, ensure random selection of herds in the site locations and adequate animal sampling within the herds. In addition to an adequate number of veterinarians for field workers and laboratory staffs to perform the serological tests.

3. Permanent and efficient animal registration systems (i.e. ear tags numbers), are needed, that would allow a reasonable compensation system to be implemented and control animal movements.

4. Appropriate funds that guarantee sustained or mid-to long term monitoring. Most of the control programmes mentioned in this study started with reasonable activities but discontinued before evaluation of the results and setting up the next program thus dangers the re-emergence of the disease in the place.

5. Depending on the prevalence of the disease in the country, a choice for, test and slaughter policy, implantation of mass vaccination programs for several years before adapting test and slaughter programmes combined with vaccination or depopulation, should be considered.

6. Culling of the infected animals should be supervised by veterinarians for safe disposable of the carcasses and avoid contamination of the environment.

7. It seems to be, the main risk factor for human brucellosis in Libya is the row milk consumption habits. Therefore, localities should be educated with the extent of the disease, the necessity of drinking pasteurised milk and that souring the milk do not kill the Brucella organism because it is preserved in the fat.

8. The only available data for human brucellosis in this study was taken from suspected cases which logically would be at a high rate of infection. This in turn did not disclose the big picture of the disease in the country. Therefore, there is a prerequisite for an active and effective surveillance system to determine the incidence of the disease in human and the related risk factor. This would allow better control for both human and animal brucellosis in the country.

Acknowledgments: This research was supported by $\mathrm{NCAH}$ in Tripoli. We thank our colleagues from National Centre of Animal Health for provided the available data and their expertise that greatly improved the manuscript.

Conflict of Interests: Authors declare that they have no conflict of interest.

\section{References}

[1] AL-GRIW, H. H., KRAIM, E. S., FARHAT, M. E., PERRETT, L. L. \& WHATMORE, A. M. (2017). "Evidence of ongoing brucellosis in livestock animals in North West Libya". J Epidemiol Glob Health. 7(4): 285-288, https://doi.org/10.1016/j.jegh.2017.09.001

[2] AZWAI, S. M., CARTER, S. D., WOLDEHIWET, Z. \& MACMILLAN, A. (2001). "Camel Brucellosis: Evaluation of field sera by conventional serological tests and ELISA". Journal of Camel Practice and Research. 8: 185-193.

[3] BEN FARAJ, S. M., AZWAI, S. M., GAMEEL, S. E., SHAREHA, A. M., BENHAJ, K. M., RAYES, H. M. \& NAYIL, A. A. (1990). "Camel and human brucellosis in Libya". International conference on camel production and improvement. Arab Center for the Studies of Arid Zones and Dry Lands, Damascus, Syria. 
[4] BLASCO, J. M. (2010). "Control and eradication strategies for Brucella melitensis infection in sheep and goats". Prilozi. 31: 145-65.

[5] EBRAHIMI, A., MILAN, J. S., MAHZOONIEH, M. R. \& KHAKSAR, K. (2014). "Shedding Rates and SeroPrevalence of Brucella melitensis in Lactating Goats of Shahrekord, Iran". Jundishapur J Microbiol, 7: e9394, https://doi.org/10.5812/jjm.9394

[6] EL-BOSHY, M., ABBAS, H., EL-KHODERY, S. \& OSMAN, S. (2009). "Cytokine response and clinicopathological findings in Brucella infected camels (Camelus dromedarius)". Veterinarni Medicina, 54(1): 25-32, https://doi.org/10.17221/3044-vetmed

[7] FAO (1999). "Transboundry Animal Disease Bulletin". EMPRES.

[8] FAO (2011). "FAO Achievements in Libya". july 2011 ed. Italy: Regional Office for the Near East; FAO. FAO Representation in Libya.

[9] FAO/WHO/OIE (1995). "Round Table on the Use of Rev1 Vaccine in Small Ruminants and Cattle". CNEVA: Alfort, France, 1995.

[10] GAMEEL, S. E., MOHAMED, S. O., MUSTAFA, A. A. \& ALZWAI, S. M. (1993). "Prevelance of Camel Brucellosis in Libya". Trop. Anim. Hlth Prod, 25(2): 91-93, https://doi.org/10.1007/bf02236513

[11] GODFROID, J., CLOECKAERT, A., LIAUTARD, J. P., KOHLER, S., FRETIN, D., WALRAVENS, K., GARINBASTUJI, B. \& LETESSON, J. J. (2005). "From the discovery of the Malta fever's agent to the discovery of a marine mammal reservoir, brucellosis has continuously been a re-emerging zoonosis". Vet.Res. 36(3): 313-326, https://doi.org/10.1051/vetres:2005003

[12] GWIDA, M., EL-GOHARY, A., MELZER, F., KHAN, I., ROSLER, U. \& NEUBAUER, H. (2012)." Brucellosis in camels". Res Vet Sci, 92: 351-5.

[13] GWIDA, M. M., EL-GOHARY, A. H., MELZER, F., TOMASO, H., ROSLER, U., WERNERY, U., WERNERY, R., ELSCHNER, M. C., KHAN, I., EICKHOFF, M., et al. (2011). "Comparison of diagnostic tests for the detection of Brucella spp. in camel sera". BMC Res Notes, 4: 525, https://doi.org/10.1186/1756-0500-4-525

[14] HEGAZY, Y. M., RIDLER, A. L. \& GUITIAN, F. J. (2009). "Assessment and simulation of the implementation of brucellosis control programme in an endemic area of the Middle East". Epidemiology and Infection. 137(10):1436-1448, https://doi.org/10.1017/s0950268809002301

[15] HOSNI, M. M. \& ABOUDAYA, M. A. (1992). "Serological survey for evidence of brucellosis in imported camels in Libya". Zag.Vet. J. (EGVMC). 20: 630-631.
[16] MORENO, E. (2014). "Retrospective and prospective perspectives on zoonotic brucellosis". Front Microbiol. 5, 213, https://doi.org/10.3389/fmicb.2014.00213

[17] MUSTAFA, A. A. \& ABUSOWA, M. (1993). "Fieldoriented trial of the Chinese Brucella suis strain 2 vaccine on sheep and goats in Libya". Vet Res. 24: 4229.

[18] NALETOSKI, I., KIRANDZISKI, T., MITROV, D., KRSTEVSKI, K., DZADZOVSKI, I. \& ACEVSKI, S. (2010). "Gaps in brucellosis eradication campaign in sheep and goats in Republic of Macedonia: lessons learned". Croat Med J. 51(4): 351-6, https://doi.org/10.3325/cmj.2010.51.351

[19] OIE (2002). "NEW ACTIVITIES OF THE VETERINARY SERVICES". Sanidad Animal Mundial. World Animal Health.

[20] OLSEN, S. C. \& STOFFREGEN, W. S. (2005). "Essential role of vaccines in brucellosis control and eradication programs for livestock". Expert Rev Vaccines. 4(6): 915-28, https://doi.org/10.1586/14760584.4.6.915

[21] PÉREZ-SANCHO, M., GARCÍA-SECO, T., DOMÍNGUEZ, L. \& ÁlVAREZ, J. (2015). "Control of Animal Brucellosis -The Most Effective Tool to Prevent Human Brucellosis". Updates on Brucellosis. https://doi.org/10.5772/61222

[22] POLYDOROU, K. (1992). "Organisation of veterinary public health activities in countries of the Eastern Mediterranean region". Rev Sci Tech. 11(1): 53-75, https://doi.org/10.20506/rst.11.1.597

[23] REFAI, M. (2002). "Incidence and control of brucellosis in the Near East region". Vet Microbiol. 90(1-4), 81-110, https://doi.org/10.1016/s03781135(02)00248-1

[24] AL TOUMEI, I. S. (2012). "Seroprevalence of human brucellosis in western region of Libya". MSc, Libyan Academy of Graduate Studies.

[25] ULLAH, R. W., WAQAS, M. Y. \& SHAH, M. A. (2014). "Epidemiology of bovine brucellosis- a review of literature". Veterinaria. 2: 16-19.

[26] WERNERY.U. (2014). "Camelid brucellosis: a review". Rev Sci Tech, 33(3): 839-57, https://doi.org/10.20506/rst.33.3.2322

[27] YANG, X., SKYBERG, J. A., CAO, L., CLAPP, B. THORNBURG, T. \& PASCUAL, D. W. (2013). "Progress in vaccine development". Front Biol (Beijing). 8, 6077.

[28] ZHANG, J., SUN, G. Q., SUN, X. D., HOU, Q., LI, M., HUANG, B., WANG, H. \& JIN, Z. (2014). "Prediction and control of brucellosis transmission of dairy cattle in Zhejiang Province". China. PLoS One. 9(11): e108592, https://doi.org/10.1371/journal.pone.0108592 